\title{
Mechanical Characteristics of 6063 Aluminum-Steel Dust Composite
}

\author{
S. O. Adeosun, E. I. Akpan, O. I. Sekunowo, W. A. Ayoola, and S. A. Balogun \\ Department of Metallurgical and Materials Engineering, University of Lagos, Lagos, Nigeria \\ Correspondence should be addressed to E. I. Akpan, emma_eia@yahoo.com
}

Received 30 May 2012; Accepted 2 July 2012

Academic Editors: J. Botsis and F. Liu

Copyright () 2012 S. O. Adeosun et al. This is an open access article distributed under the Creative Commons Attribution License, which permits unrestricted use, distribution, and reproduction in any medium, provided the original work is properly cited.

Studies on the effect of steel dust (EAF dust) addition on the mechanical properties of 6063 Aluminium alloy have been carried out. The cast composite samples contain steel dust from $2-20 \mathrm{wt} \%$ produced in sand mould. These cast samples were homogenized, cold rolled, and solution-treated. The solution treated samples were normalized in still air, some quenched in water while some were tempered after quenching. Tensile and hardness responses were determined in all these processed samples. The results obtained reveal that $10 \mathrm{wt} \%$ steel dust in aluminium 6063 improved the ultimate tensile strength to $111.09 \mathrm{MPa}$ and a corresponding hardness of 51.2 HV. Microstructural analysis shows iron containing intermetallics which are well distributed in the matrix with its morphology depending on the heat treatment and deformation imposed on them. Tensile strength and hardness of the composites was also found to depend on the volume fraction of intermetallics in the matrix.

\section{Introduction}

Aluminum alloys find extensive usage in engineering applications due to its high specific strength (strength/density). These alloys are basically used in applications requiring lightweight materials, such as aerospace and automobiles. The 6xxx-group alloys have a widespread application, especially in the building, aircraft, and automotive industry due to their excellent properties [1-3]. The 6 xxx series contain $\mathrm{Si}$ and $\mathrm{Mg}$ as main alloying elements. These alloying elements are partly dissolved in the primary $\alpha$-Al matrix, and partly present in the form of intermetallic phases. A range of different intermetallic phases may form during solidification, depending on alloy composition and solidification condition. Relative volume fraction, chemical composition, and morphology of structural constituents exert significant influence on their useful properties [4-12].

Previous research on the improvement of mechanical properties has been focused on heat treatment, precipitation, and age hardening [7-13]. Authors have noted that the formation and precipitation of intermetallics such as Al-Fe$\mathrm{Si}$ and Al-Fe-Si-Mn have significant influence on the useful properties of 6xxx group of alloys if controlled [8-12]. Other research has also focused on the addition of elements and particles to the $6 \mathrm{xxx}$ matrix in order to improve its mechanical properties.

Khraisat and Jadayil [14] studied the effect of strengthening aluminium scrap using iron powder in order to achieve better mechanical properties. Superior properties were observed in cast aluminium with $1 \mathrm{wt} . \%$ iron addition. The mechanical behaviour of an alloy based on $\mathrm{Fe}-40 \mathrm{Al}$ prepared from mechanically alloyed powders was examined over a wide temperature range in the fine-grained, as-extruded state as well as after recrystallization by Morris and Gunther [15]. The study revealed that fine-grained material possesses improved strength and reasonable ductility at room temperature, in contrast with the weaker and more brittle largegrained material. However, at high temperature, the strength of both materials dropped. Sasaki et al. [16] characterized consolidated nanocrystalline Al-5 wt.\% Fe alloy powders produced by mechanical alloying using spark plasma sintering. The sintered sample showed high strength with a large plastic strain of $15 \%$ at room temperature. Singh [17] also studied the peculiarities of aluminium-iron ore in-situ particulate composites. The strength and hardness values for the composites showed considerable improvement over the values for other composites. Darvishi et al. [18] examined the effect of iron and manganese concentration on the 
morphology of complex intermetallics and their influence on the mechanical properties and microstructure of Al$16.67 \mathrm{wt} . \%$ Si alloy using $0.4,1.2,1.8 \mathrm{wt} . \%$ iron contents and manganese contents of 0.6 and $0.9 \mathrm{wt} . \%$. The results of UTS show that when iron increases, the UTS steadily decreases from $229 \mathrm{MPa}$ of $0.4 \mathrm{wt} . \%$ of iron to $187 \mathrm{MPa}$ when iron content reaches 1.8 wt.\%. But the hardness increased from 104 to $130 \mathrm{HV}$ as iron content increased from 0.4 to 1.8 wt.\%. Orozco-Gonzàlez et al. [3] also examined the effect of iron addition on the structure of intermetallics formed in $\mathrm{Al}$ alloys. The study shows that for Al-Fe-Mn-Si alloys with $\mathrm{Fe} / \mathrm{Mn}$ weight ratios up to 4 , the $\alpha$-phase had cubic crystal structure, while for alloys with Fe/Mn weight ratio of 5.3 or more, the $\alpha$-phase had hexagonal crystal structure. The tensile behaviour of composites produced by infiltrating ceramic particle in $\mathrm{Al}$ matrix has been studied as a function of reinforcement size and chemistry $\left(\mathrm{Al}_{2} \mathrm{O}_{3}\right.$ and $\left.\mathrm{B}_{4} \mathrm{C}\right)$ [19]. An earlier research on the use of ceramic particles was conducted by Shih-Chang and Sinn-Wen [20]. Both authors reported strengthening due to the reinforcements. Silicon carbide has also been used as reinforcement to strengthen $\mathrm{Al}$ alloys [21]. Mechanical properties of Dispersion-strengthened-cast aluminium (DSC-Al-Sc $(-\mathrm{Zr})$ ) alloys containing two distinct populations of dislocation impeding particles: a high volume fraction of submicron, incoherent $\mathrm{Al}_{2} \mathrm{O}_{3}$ dispersoids and a low volume fraction of nanometer-size, coherent $\mathrm{Al}_{3} \mathrm{Sc}$ precipitates, have also been examined [22]. Results showed that the alloy exhibits strengthening at ambient temperature from both the $\mathrm{Al}_{3} \mathrm{Sc}$ precipitates and the $\mathrm{Al}_{2} \mathrm{O}_{3}$ dispersoids, as measured by microhardness and uniaxial compressive testing. This paper examines the mechanical responses of aluminium alloy infiltrated with steel dust particles.

Thousands of tons of electric arc furnace (EAF) dust are generated in metallurgical plants each year. These dusts are waste and dumped considering environmental regulations. They are not easily disposed since they are considered toxic because it contains small amounts of $\mathrm{Pb}$, As, and $\mathrm{Cr}$ oxides which are formed at high temperatures above the steel bath and in the off-gas systems. Overall, EAF dusts contain major elements of the type iron, zinc, calcium, manganese, magnesium, and silicon in the form of simple or mixed oxides. Spectrometric analysis of steel dust shows that it contains considerable amount of iron, manganese, and silicon in oxide form. These oxides when added to aluminium may serve as microadditions and being in oxide form may lead to improved properties of the 6xxx series alloys. The purpose of this research, therefore, is to experimentally investigate the effect of addition of the EAF dust on the mechanical properties of $6063 \mathrm{Al}$ alloy.

\section{Experimental Methodology}

The AA6063 aluminum alloy used in this study was provided by Nigerian Aluminum Extrusion Company (NIGALEX), Oshodi, Lagos, with chemical composition given in Table 1. Steel dust, used for reinforcement in the aluminium alloy was obtained from Universal Steel Company, Ogba, Ikeja, Nigeria. The apparatus used in the melting, casting process,
TABLE 1: Spectrometric analysis of aluminium 6063 alloy.

\begin{tabular}{lcccccccc}
\hline Element & $\mathrm{Si}$ & $\mathrm{Fe}$ & $\mathrm{Cu}$ & $\mathrm{Mn}$ & $\mathrm{Zn}$ & $\mathrm{Cr}$ & $\mathrm{Ti}$ & $\mathrm{Al}$ \\
\hline$\%$ & 0.429 & 0.225 & 0.004 & 0.026 & 0.002 & 0.006 & 0.033 & 98.85 \\
Composition & & & & & & & & \\
\hline
\end{tabular}

and analysis are 2-high rolling mills, digital Metallurgical microscope, Polishing machine, Grinding machine, Universal testing machine, Brinell Hardness tester, Crucible pot, Diesel-fired furnace, Tongs, Shovel, Hand gloves, Eye goggles, Mass balance, Water, Green sand, Emery paper, Etchant (dilute sodium hydroxide), Sieve, Mould boxes, Wooden pattern, and Rammer.

Billets of AA6063 aluminium alloy were cut and charged into a diesel-fired crucible furnace, melted at $700^{\circ} \mathrm{C}$ and cast into cylindrical form in a metal mould. The melted aluminium alloy was mixed with steel dust in proportions of $2,5,10,15,20$ wt. $\%$ to obtain the batches of the composite cast samples. The composite charge was now brought out with the help of long metal tongs, stirred with an iron rod to skim off slag suspensions, poured into the mould, and was left to solidify. After about 1 hour the solidified cast was removed, cleaned and homogenised at $520^{\circ} \mathrm{C}$ for 2 hours in the box-type furnace. These homogenized composite samples were given $20 \%$ thickness reduction at ambient temperature $\left(31^{\circ} \mathrm{C}\right)$ in a 2-high rolling mill leaving some as control. All samples were grouped for further processing as shown below.

(1) Homogenized without further treatment-SH (control sample).

(2) Homogenized, cold rolled, solution heat treated and Normalized-SHRN.

(3) Homogenized, cold rolled, solution heat treated and quenched-SHRQ.

(4) Homogenized, cold rolled, solution heat treated, quenched and tempered at $170^{\circ} \mathrm{C}$ and for 8 hours (T6 temper state)-SHRT.

A Leco microhardness tester LM 700AT machine was used for the Rockwell hardness of the samples. Tensile test of samples was carried out using Testomeric AXM500-25 KN (Testomeric UK) machine. All tests were conducted according to ASTM E8 specification. Metallographic examination was carried out on each sample after the surfaces were ground, polished using a mixture of alumina etched in a solution containing 1 gram sodium hydroxide in $100 \mathrm{mLs}$ of water for 20 secs. The prepared sample surfaces was dried in still air and the morphology of the samples were then examined with a digital metallurgical microscope at $\times 200$ magnification. The photomicrographs of the composite samples morphologies are shown in Figures 5-8.

\section{Results}

3.1. Mechanical Properties. The results of the mechanical properties are shown in Figures 1-4. These figures give a summary of the ultimate tensile strength (UTS), Rockwell 
TABLE 2: Spectrometric analysis of EAF steel dust.

\begin{tabular}{lcccccccccccc}
\hline Element & $\mathrm{Fe}_{2} \mathrm{O}_{3}$ & $\mathrm{MnO}$ & $\mathrm{SiO}_{2}$ & $\mathrm{ZnO}$ & $\mathrm{Na}_{2} \mathrm{O}$ & $\mathrm{MgO}$ & $\mathrm{Al}_{2} \mathrm{O}_{3}$ & $\mathrm{CaO}$ & $\mathrm{Ni}_{2} \mathrm{O}_{3}$ & $\mathrm{~K}_{2} \mathrm{O}$ & $\mathrm{PbO}$ \\
\hline Composition \% & 48.8 & 6.3 & 17.8 & 6.5 & 1.3 & 4.6 & 0.6 & 5.9 & 5.7 & 1.4 & 1.1 \\
\hline
\end{tabular}

TABLE 3: Variation of ultimate tensile strength values with wt.\% steel dust addition.

\begin{tabular}{lcccccc}
\hline Steel dust (wt.\%) & As cast + rolled & As cast & SH & SHRN & SHRQ & SHRT \\
\hline 0 & 99.5 & 79.45 & 75.31 & 75.42 & 99.8 & 86.06 \\
2 & 101.9 & 101.62 & 70.6 & 89.86 & 89.63 \\
5 & 84 & 111.09 & 74.12 & 107.56 & 102.4 & 93.97 \\
10 & 68.4 & 81.09 & 59.58 & 86.6 & 72.99 & 103.02 \\
15 & 77 & 70.6 & 74.12 & 98.27 & 74.8 & 124.46 \\
20 & 86.8 & 76.17 & 63 & 91.88 & 91.4 & 68.89 \\
\hline
\end{tabular}

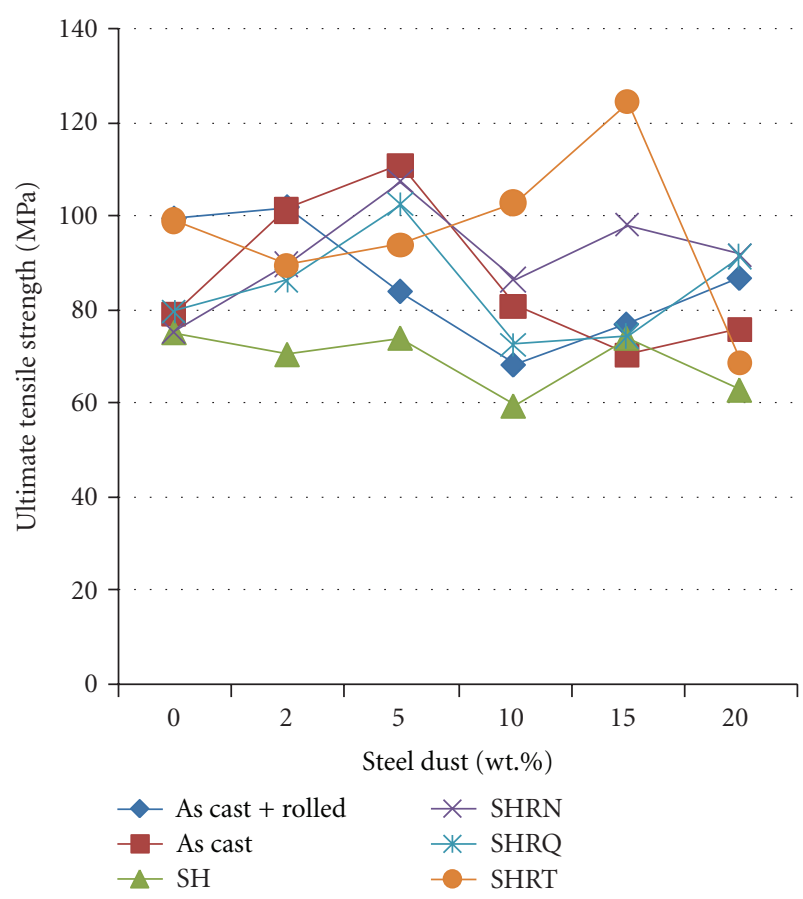

FIGURE 1: Ultimate tensile strength against \% steel dust addition.

hardness number, and percentage elongation as a function of the percentage addition of steel dust. Figure 1 shows the variation of ultimate tensile strengths (UTS) with percent volume of steel dust in the aluminium. The UTS of the homogenized composite sample increases as the addition of steel dust increases to a peak value of $111 \mathrm{MPa}$ at wt.10\% steel dust addition. Further increase in steel dust addition resulted in a decline in the UTS to $70 \mathrm{MPa}$ reached at $20 \mathrm{wt} . \%$ steel dust. For the SHRN and SHRQ composite samples the trend in UTS variation with percentage composition of dust is comparable to that of SH sample with maximum UTS of $108 \mathrm{MPa}$ and $102 \mathrm{MPa}$, respectively, at $10 \mathrm{wt} . \%$ steel dust addition. The UTS declines as more steel dust is added in both processed sample groups. Tempered samples showed appreciable increase in the UTS as the wt.\% steel dust addition increases

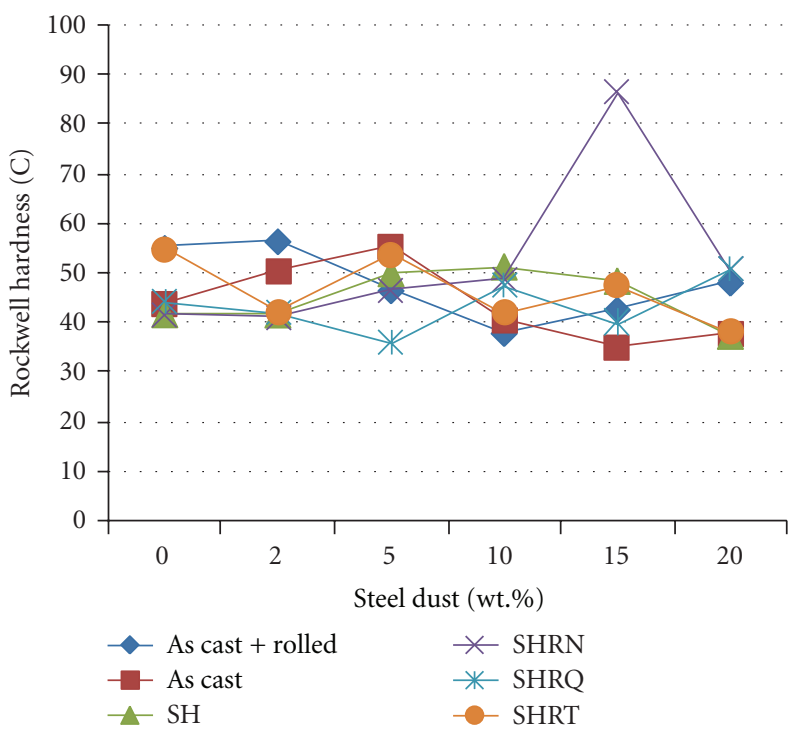

Figure 2: Hardness values against wt.\% steel dust.

to a peak value (124 MPa) at $15 \mathrm{wt} . \%$ steel dust and thereafter declines (Tables 3,4 , and 5).

The Rockwell hardness values of the aluminium-steel dust composite are shown in Figure 2. But for the SHRN sample, increase in the percentage steel dust addition was accompanied with corresponding increase in the hardness values and it reached a maximum value of 86 HRC at $15 \%$ after which the hardness value declines. Hardness of homogenized and SHRQ samples increased to a maximum value of $51.2 \mathrm{HRC}$ and $47.4 \mathrm{HRC}$, respectively, at $10 \mathrm{wt} . \%$ of steel dust in the aluminium alloy. The tempered composite samples have $54.1 \mathrm{HRC}$ at $5 \mathrm{wt} . \%$ steel dust and $47.7 \mathrm{HRC}$ at 15 wt. $\%$ steel dust.

The strain values of the aluminium-steel dust composite are shown in Figures 3 and 4. Both strain at fracture and strain at ultimate tensile strength show appreciable response to normalizing and quenching treatments. Strain values were higher for these treatments (SHRN and SHRQ see Figures 3 and 4) than for any other treatment in all cases. Strain rises 
TABLE 4: Variation of strain (at UTS) values with \% steel dust addition.

\begin{tabular}{|c|c|c|c|c|c|c|}
\hline Steel dust (wt.\%) & As cast + rolled & As cast & $\mathrm{SH}$ & SHRN & SHRQ & SHRT \\
\hline 0 & 14.7 & 15.4 & 13.85 & 15.26 & 16.5 & 14.87 \\
\hline 2 & 16.6 & 15.3 & 16.7 & 28.4 & 24 & 14.67 \\
\hline 5 & 10 & 21.34 & 9.18 & 33.77 & 30.8 & 15.43 \\
\hline 10 & 6.16 & 10.84 & 9.16 & 27.97 & 23.7 & 7.91 \\
\hline 15 & 10.4 & 7.41 & 9.18 & 35.14 & 36.2 & 14 \\
\hline 20 & 10.5 & 12.99 & 7.41 & 18.3 & 21.7 & 9.26 \\
\hline
\end{tabular}

TABLE 5: Variation of hardness values with \% steel dust.

\begin{tabular}{lcccccc}
\hline Steel dust addition \% & As cast + rolled (HRC) & As cast (HRC) & SH (HRC) & SHRN (HRC) & SHRQ (HRC) & SHRT (HRC) \\
\hline 0 & 55.28 & 44.14 & 41.84 & 41.90 & 44.33 & 55.03 \\
2 & 56.61 & 50.81 & 41.80 & 41.40 & 41.90 & 42.40 \\
5 & 46.67 & 55.55 & 49.90 & 46.90 & 36.10 & 54.10 \\
10 & 38.00 & 40.55 & 51.20 & 48.90 & 47.40 & 42.10 \\
15 & 42.78 & 35.30 & 48.40 & 86.60 & 40.10 & 47.70 \\
20 & 48.22 & 38.09 & 37.60 & 51.04 & 50.78 & 38.27 \\
\hline
\end{tabular}

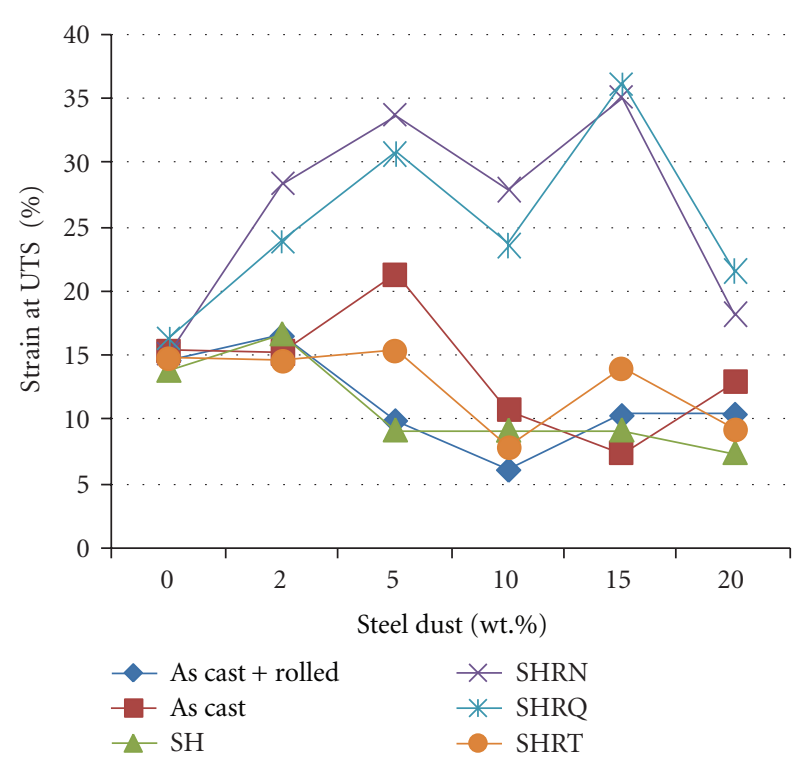

FIGURE 3: Variation of strain (at the ultimate tensile strength) with wt. $\%$ steel dust addition.

to maximum at $15 \mathrm{wt} . \%$ steel dust addition for both SHRN (35\%) and SHRQ (36\%) after which it declines.

3.2. Microstructure. The microstructures of processed cast samples are given in Figures 5-8. The microstructure of aluminium steel dust composite each containing $2 \mathrm{wt} \% \%$ steel dust is shown in Figure 5. In the SH matrix (Figure 5(a)) $\mathrm{Mg}_{2} \mathrm{Si}$ are fairly distributed along the grain boundaries of the $\mathrm{Al}$ matrix. The weight fraction of $\mathrm{Al}_{5} \mathrm{FeSi}$ crystals which appears plate-like phase is higher than other intermetallics in the matrix, while spherical crystals of $\mathrm{Al}_{12}(\mathrm{Fe}, \mathrm{Mn})_{3} \mathrm{Si}$ phase is randomly distributed in the matrix. In the SHRN (Figure 5(b)) sample matrix, the crystals of $\mathrm{Mg}_{2} \mathrm{Si}$ phase is fine and well distributed over the matrix surface. The

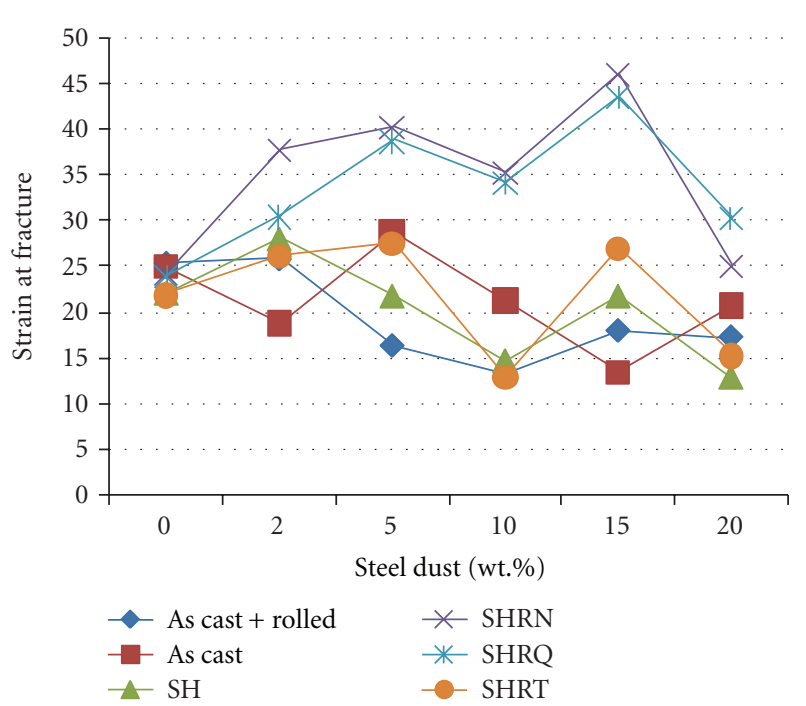

FIGURE 4: Variation of strain (at fracture) with wt.\% steel dust addition.

spherical crystals of $\mathrm{Al}_{12}(\mathrm{Fe}, \mathrm{Mn})_{3} \mathrm{Si}$ phase are not strongly precipitated as in "a" while the weight fraction of $\mathrm{Al}_{5} \mathrm{FeSi}$ phase is substantial in the matrix. In the SHRQ (Figure 5(c)) sample, the plate-like phase is absent. Spherical crystals of $\mathrm{Al}_{12}(\mathrm{Fe}, \mathrm{Mn})_{3} \mathrm{Si}$ phase are sparsely distributed and clustering of $\mathrm{Mg}_{2} \mathrm{Si}$ crystals is pronounced in this matrix. In the SHRT sample, the matrix contain crystals of $\mathrm{Mg}_{2} \mathrm{Si}$ phase that are finely distributed, with few spherical crystals of $\mathrm{Al}_{12}(\mathrm{Fe}, \mathrm{Mn})_{3} \mathrm{Si}$ phase. The plate-like crystals of $\mathrm{Al}_{5} \mathrm{FeSi}$ phase are fairly distributed in the matrix.

Figure 6 reveals the morphologies of the composite samples at $5 \mathrm{wt} \%$ steel dust. The SH sample matrix contain plate-like crystals of which are $\mathrm{Al}_{5} \mathrm{FeSi}$ phase randomly distributed which are dominant intermetallics and the $\mathrm{Mg}_{2} \mathrm{Si}$ crystals are sparsely distributed. The SHRN sample has fine 


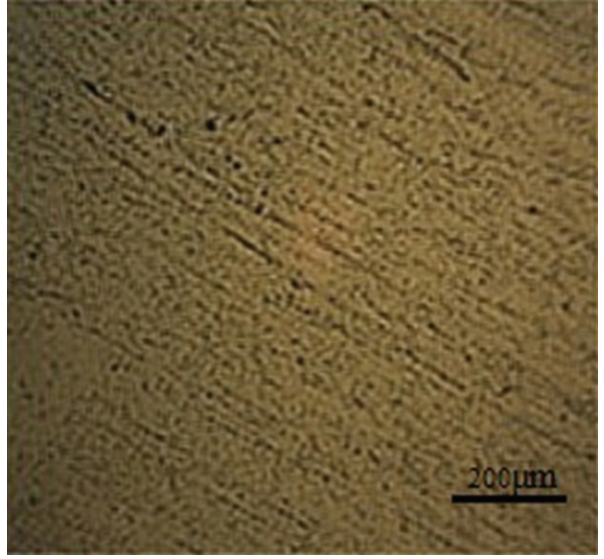

(a)

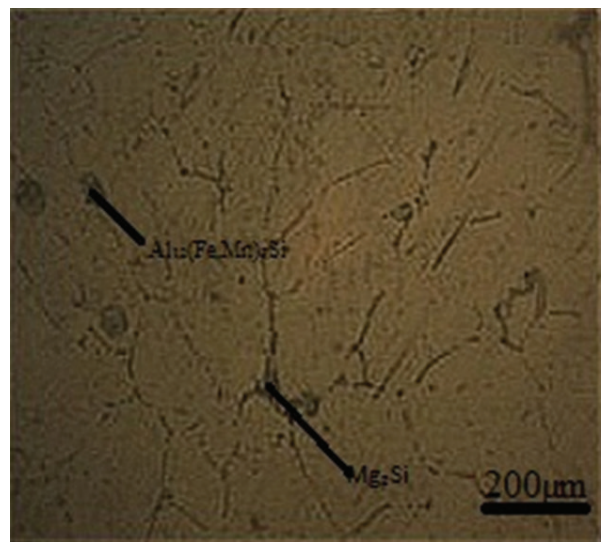

(c)

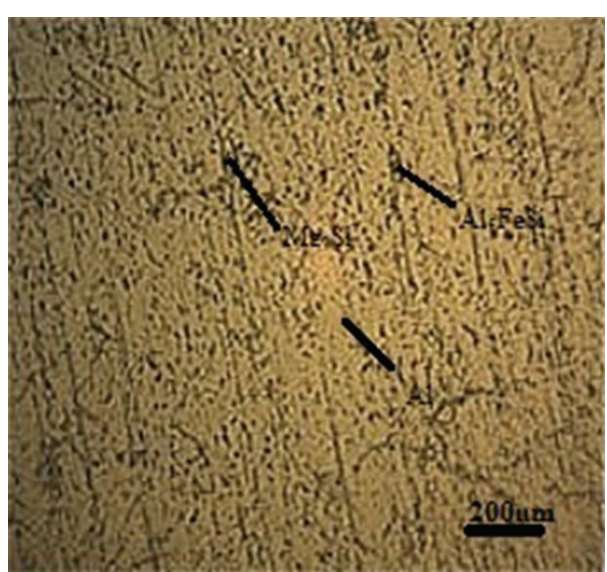

(b)

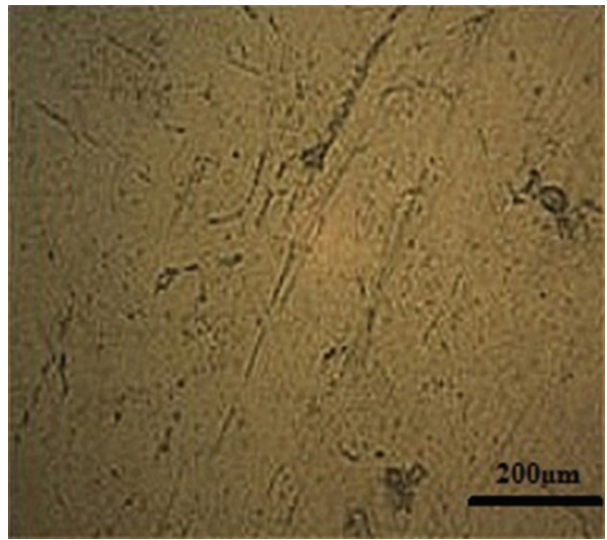

(d)

FIgURE 5: Microstructure of 6063 aluminium alloy with 2\% steel dust addition: (a) SH, (b) SHRN, (c) SHRQ, (d) SHRT.

crystals when compared with the SH sample. The plate-like crystals of $\mathrm{Al}_{5} \mathrm{FeSi}$ phase are distributed in the matrix while the spherical crystals of $\mathrm{Al}_{12}(\mathrm{Fe}, \mathrm{Mn})_{3} \mathrm{Si}$ phase are faintly distributed. In the SHRQ sample, the volume distribution of crystals of $\mathrm{Al}_{12}(\mathrm{Fe}, \mathrm{Mn})_{3} \mathrm{Si}$ phase is stronger in this matrix than that in SHRN sample matrix. Crystals of $\mathrm{Al}_{5} \mathrm{FeSi}$ phase are also observed in this matrix. In the SHRT matrix, the crystals of $\mathrm{Al}_{5} \mathrm{FeSi}$ phase are randomly distributed while this phase volume fraction dominates other precipitated intermetallics in the matrix with sparse crystals of $\mathrm{Al}_{12}(\mathrm{Fe}, \mathrm{Mn})_{3} \mathrm{Si}$ phases seen in the matrix.

In the micrograph the SH sample containing $10 \mathrm{wt} . \%$ steel dust, spherical crystals of $\mathrm{Al}_{12}(\mathrm{Fe}, \mathrm{Mn})_{3} \mathrm{Si}$ are precipitated and are well distributed in the matrix. Crystals of $\mathrm{Mg}_{2} \mathrm{Si}$ are also visibly present in the matrix. The SHRN sample contains increased volume fraction of $\mathrm{Al}_{12}(\mathrm{Fe}, \mathrm{Mn})_{3} \mathrm{Si}$ crystals improved compared to that observed in $\mathrm{SH}$ sample with the $\mathrm{Mg}_{2} \mathrm{Si}$ crystals being fairly distributed. There is increased precipitation of $\mathrm{Al}_{5} \mathrm{FeSi}$ crystals in the SHRQ sample than in the SH and SHRN samples. Micrograph of SHRQ sample shows the plate-like crystals of $\mathrm{Al}_{5} \mathrm{FeSi}$ being randomly distributed in the matrix, the spherical crystals of $\mathrm{Al}_{12}(\mathrm{Fe}, \mathrm{Mn})_{3} \mathrm{Si}$ fairly distributed with reduction in the volume fraction of $\mathrm{Mg}_{2} \mathrm{Si}$ crystals precipitated in the matrix (see Figure 7).
Microstructures for $\mathrm{Al}$ alloy composites with $20 \mathrm{wt} . \%$ addition of steel dust addition are shown in Figure 8. The micrographs show that in the $\mathrm{SH}$ sample the $\mathrm{Mg}_{2} \mathrm{Si}$ crystals are sparsely distributed while spherical crystals of $\mathrm{Al}_{12}(\mathrm{Fe}, \mathrm{Mn})_{3} \mathrm{Si}$ though smaller in size are randomly distributed in the matrix. The crystals of $\mathrm{Al}_{5} \mathrm{FeSi}$ are also precipitated in the matrix. In the $\mathrm{SHRN} \mathrm{Al}_{12}(\mathrm{Fe}, \mathrm{Mn})_{3} \mathrm{Si}$ dominates in volume fraction of the intermetallics precipitated. The $\mathrm{Mg}_{2} \mathrm{Si}$ crystals are present in minor volume fraction. The SHRQ sample has very fine crystals compared to SHRN sample and $\mathrm{Al}_{5} \mathrm{FeSi}$ crystals are fairly distributed within the matrix and randomly distributed $\mathrm{Al}_{12}(\mathrm{Fe}, \mathrm{Mn})_{3} \mathrm{Si}$. In the SHRQ sample, $\mathrm{Al}_{5} \mathrm{FeSi}$ crystals are fairly with $\mathrm{Al}_{12}(\mathrm{Fe}, \mathrm{Mn})_{3} \mathrm{Si}$ phase been strongly precipitated in the matrix. The presence of crystals of $\mathrm{Mg}_{2} \mathrm{Si}$ is visible in the matrix.

\section{Discussion}

The results of adding steel dust powder to 6063 aluminium alloy indicate marked effect on the tensile strength, ductility, and hardness properties of the alloy. The UTS result of these processed samples show significant improvement over the conventional 6063 aluminium alloy. This can be attributed to the combined effect of grain refinement propelled by increase 


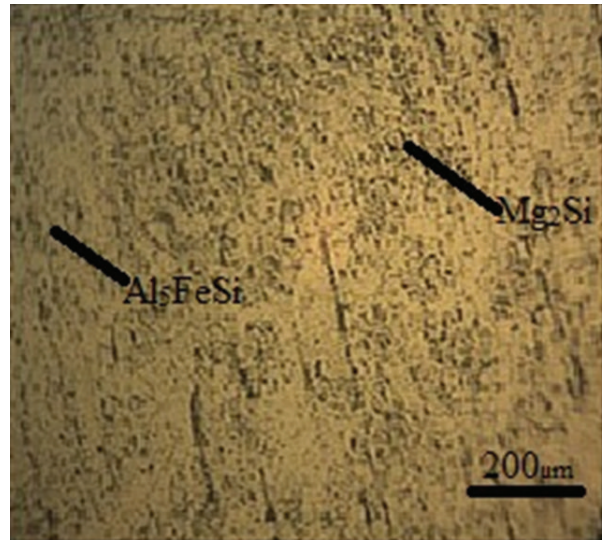

(a)

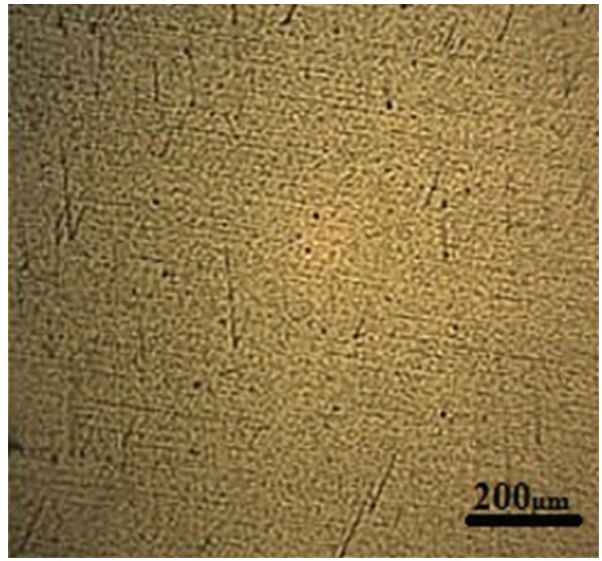

(c)

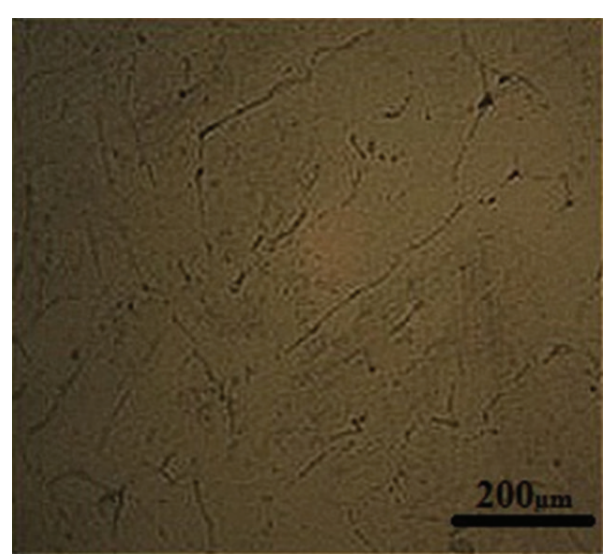

(b)

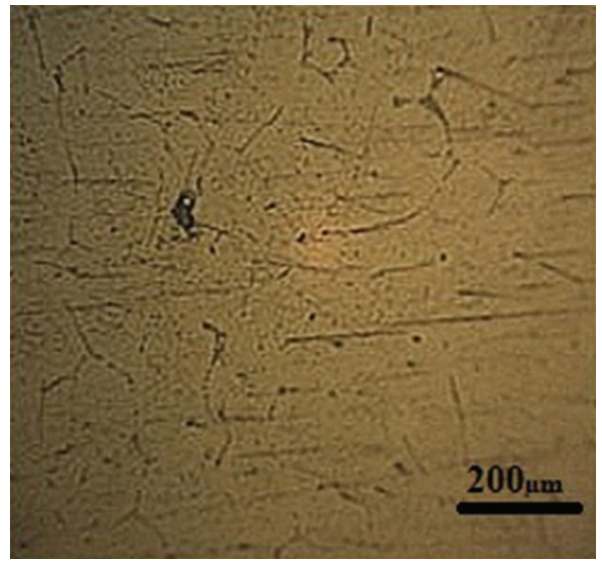

(d)

FIGURE 6: Micrographs showing 6063 aluminium alloy with 5\% steel dust addition: (a) SH, (b) SHRN, (c) SHRQ, (d) SHRT.

in iron content and the formation, precipitation, and distribution of hard intermetallic compounds $\left(\mathrm{Al}_{12}(\mathrm{Fe}, \mathrm{Mn})_{3} \mathrm{Si}\right)$ at the grain boundaries of the $\mathrm{Al}$ alloy during solidification $[4,12,14,23]$.

It is evident from the results that heat treatment processes aside mere homogenization do not impart any marked improvement on the mechanical properties of the material composite samples. This could be attributed to the fact that during homogenization an otherwise perfect structure is formed with the intermetallics well distributed to obtain optimum properties such that further treatment (cold rolling, normalizing, quenching, etc.) will only lead to a distortion of the otherwise perfect structure. This is evident from Figure 7(b) which shows that the smallsized crystals of $\left(\mathrm{Al}_{12}(\mathrm{Fe}, \mathrm{Mn})_{3} \mathrm{Si}\right)$ intermetallics are found evenly distributed in Figure 7(a) and were redistributed with crystal clustering and crystal coarsening as a result of the rolling and subsequent normalizing processes. SH samples showed superior tensile properties compared to all other samples subjected to further treatments. This is evident from the microstructure of the homogenized samples in Figures 5(a), 6(a), 7(a), and 8(a) showing distribution of the hard intermetallics $\left(\mathrm{Al}_{12}(\mathrm{Fe}, \mathrm{Mn})_{3} \mathrm{Si}\right)$ over the $\mathrm{Al}$ matrix leading to improved tensile properties.
It is observed from the mechanical properties of $\mathrm{SH}$ samples that increase in the amount of steel dust leads to increase in UTS (Figure 1) attaining a peak value at $10 \mathrm{wt} . \%$ steel dust addition after which the UTS decreases. The strength of the material increases initially due to the increase in the amount of iron in the composition which led to grain refinement and subsequent precipitation of hard intermetallics. This trend is also seen in the work of Khraisat and Abu Jadayil [14]. During casting of 6063 aluminium alloys a wide variety of Fecontaining intermetallics such as $\mathrm{Al}-\mathrm{Fe}, \mathrm{Al}-\mathrm{Fe}-\mathrm{Si}$, and $\mathrm{Al}-\mathrm{Fe}-$ $\mathrm{Mn}-\mathrm{Si}$ phases are formed between the aluminium $[12,23]$. The process of the alpha $\mathrm{Al}_{12}(\mathrm{Fe}, \mathrm{Mn})_{3} \mathrm{Si}$ phase formation is controlled by chemical composition of the alloy, but in the case of the nonequilibrium conditions the local fluctuations of the $\mathrm{Fe}, \mathrm{Mn}$, and $\mathrm{Si}$ concentrations decide the precipitation course [24]. Tables 1 and 2 indicate that the amount of Fe, $\mathrm{Mn}$, and Si will increase as the percentage of the steel dust in aluminium alloy increases due to their presence in the steel dust. However, the increase in Fe content can cause distinct growth in volume fraction of alpha- $\mathrm{Al}_{12}(\mathrm{Fe}, \mathrm{Mn})_{3} \mathrm{Si}$ phase particles (because of the very low solubility of these elements in $\mathrm{Al}$ ) with changes in its morphology and size depending on the $\mathrm{Fe}: \mathrm{Mn}$ ratio [24]. As the volume fraction of iron formed intermetallics increases in the matrix, the UTS 


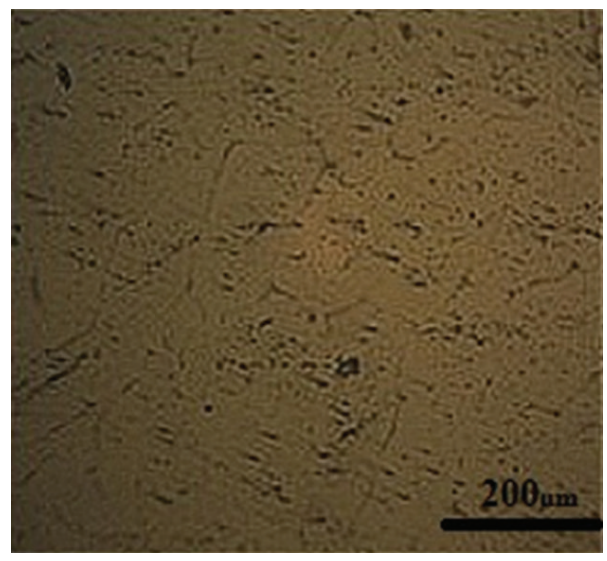

(a)

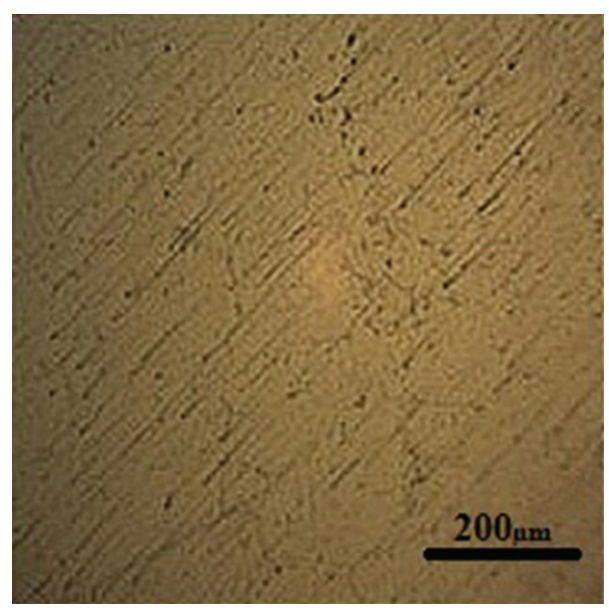

(c)

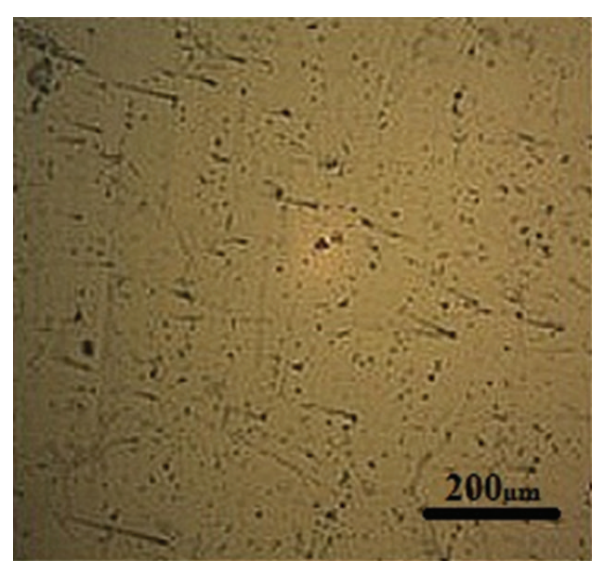

(b)

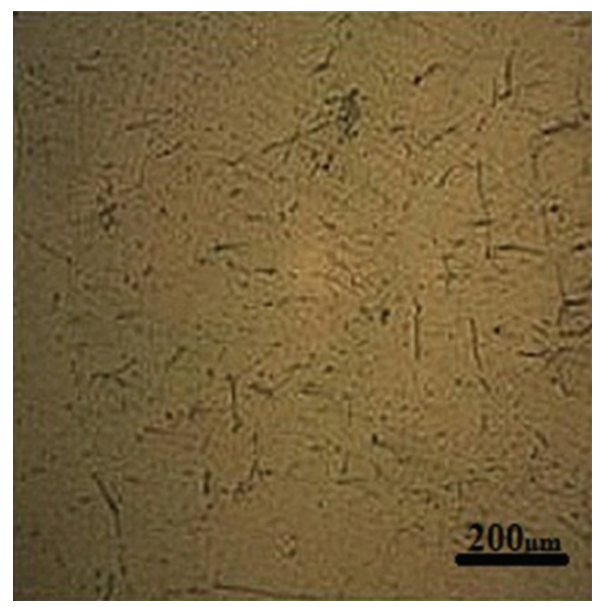

(d)

Figure 7: Micrographs showing 6063 aluminium alloy with 10\% steel dust addition: (a) SH, (b) SHRN, (c) SHRQ, (d) SHRT.

becomes lower. The reason that iron-containing intermetallic particles are detrimental to mechanical properties could be because they are hard and are therefore much more easily fractured under the tensile load than the aluminium matrix, the tendency increasing as the amount of the intermetallics increases. This agrees with the work of Darvishi et al. [18] who reported that the UTS of Al-16.6Si alloy decrease with a higher amount iron.

The effect of steel dust on the microhardness of aluminium alloys showed that as dust levels increase from 0 to $10 \mathrm{wt} . \%$, the hardness of Al-Si-based alloys increases (see Figure 2) for SH samples but decrease afterwards. The microhardness values for SHRN, SHRQ, and SHRT samples have no specific trend. The effect of steel dust on hardness can be described by the size and volume fraction of ironcontaining intermetallics (particularly alpha $\mathrm{Al}_{12}(\mathrm{Fe}, \mathrm{Mn})_{3} \mathrm{Si}$ ) which increased with iron content. However, as steel dust increases, iron level increases giving rise to increase in porosity (compare Figures $7(\mathrm{a})$ and $8(\mathrm{a})$ ) and which affect significantly the hardness responses of the aluminium composite samples.

Results also show that ductility of the Al-Si-based alloy was influenced by the amount of steel dust addition. Though no specific trend in the variation of strain with wt.\% steel dust addition could be noticed (see Figures 3 and 4), it could be observed that the steel dust addition has a significant effect on the strain values. Normalized (SHRN) and quenched (SHRQ) samples had maximum strain values compared to any other treatment. During normalizing, the homogenized material is allowed to cool in still air allowing crystal coarsening and clustering. This is evident from Figure 7(b) which shows the small sized crystals of $\left(\mathrm{Al}_{12}(\mathrm{Fe}, \mathrm{Mn})_{3} \mathrm{Si}\right)$ intermetallics which were evenly distributed in Figure 7(a), redistributed with crystal clustering and coarsening as a result of the rolling and subsequent normalizing processes. During quenching (SHRQ) crystal growth is minimized. However, precipitation of $\mathrm{Al}_{5} \mathrm{FeSi}$ occurs in the matrix in small volume fraction (see Figure 7(c)) which supports ductility. These results are in support of the findings of Sasaki et al. [25] and Zajac et al. [26] who explained that the $\mathrm{Al}_{5} \mathrm{FeSi}$ crystals when they are round and in small volume fraction support elongation.

\section{Conclusion}

The effect of steel dust addition on the mechanical properties of 6063 Aluminium alloy has been studied. It was observed that there was considerable improvement in the mechanical 


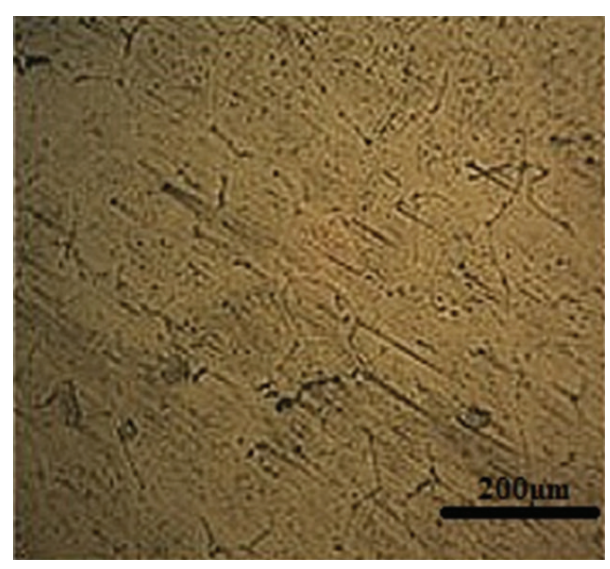

(a)

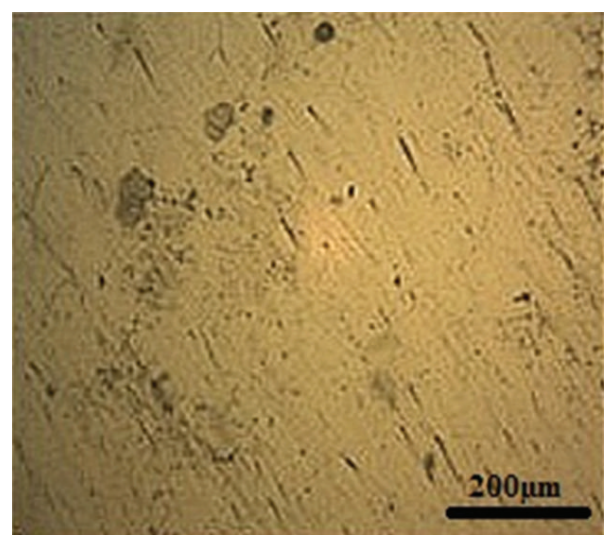

(c)

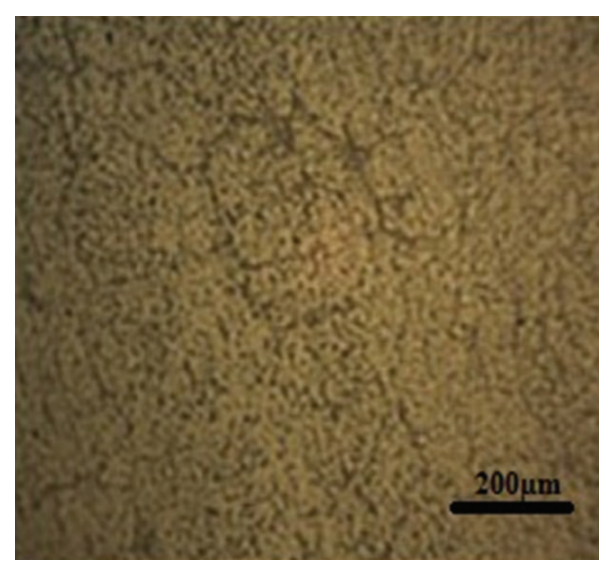

(b)

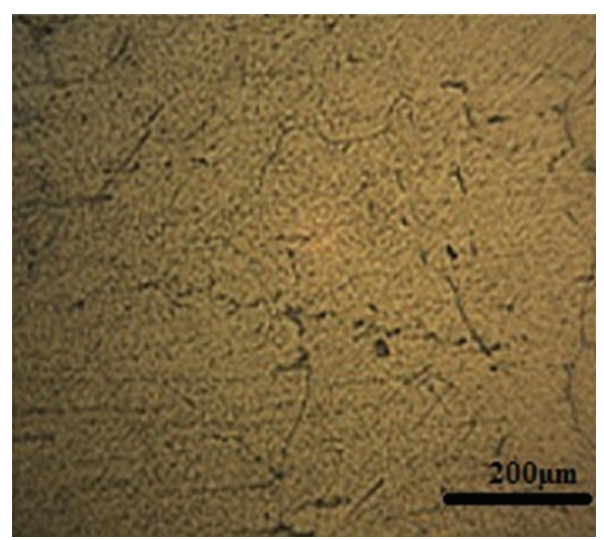

(d)

FIGURE 8: Micrographs showing 6063 aluminium alloy with 20\% steel dust addition: (a) SH, (b) SHRN, (c) SHRQ, (d) SHRT.

properties of the alloy with the steel dust addition. The maximum UTS of $111 \mathrm{MPa}$ for the as-cast condition was obtained for $10 \mathrm{wt} . \%$ steel dust addition, compared with the UTS of control sample of $79 \mathrm{MPa}$ and the standard UTS of 6063 aluminium alloy of $90 \mathrm{MPa}$. The maximum hardness value of $51.2 \mathrm{HRC}$ for the as-cast condition was obtained at $10 \mathrm{wt} . \%$ steel dust addition, compared with the hardness value of control sample of $43.8 \mathrm{HRC}$ and the standard hardness value for 6063 aluminium alloy of 43 HRC.

\section{References}

[1] G. Mrówka-Nowotnik and J. Sieniawski, "Influence of heat treatment on the microstructure and mechanical properties of 6005 and 6082 aluminium alloys," in Proceedings of the 13th Scientific International Conference on Achievements in Mechanical and Materials Engineering, pp. 447-450, 2005a.

[2] G. Mrówka-Nowotnik and J. Sieniawski, "Influence of heat treatment on the microstructure and mechanical properties of 6005 and 6082 aluminium alloys," Journal of Materials Processing Technology, vol. 162-163, pp. 367-372, 2005b.

[3] P. Orozco-Gonzàlez, M. Castro-Romàn, J. López-Rueda et al., "Effect of iron addition on the crystal structure of the $\alpha$-AlFeMnSi phase formed in the quaternary Al-Fe-Mn-Si system," Revista de Metalurgia, vol. 47, no. 6, pp. 453-461, 2011.
[4] G. Mrówka-Nowotnik, J. Sieniawski, and A. Nowotnik, "Tensile properties and fracture toughness of heat treated 6082 alloy," Journal of Achievements in Materials and Manufacturing Engineering, vol. 17, no. 1-2, pp. 1-2, 2006.

[5] S. Karabay, M. Zeren, and M. Yilmaz, "Investigation of extrusion ratio effect on mechanical behaviour of extruded alloy AA-6101 from the billets homogenised-rapid quenched and as-cast conditions," Journal of Materials Processing Technology, vol. 160, no. 2, pp. 138-147, 2005.

[6] M. Warmuzek, J. Sieniawski, A. Gazda, and G. Mrówka, "Analysis of phase formation in AlFeMnSi alloy with variable content of Fe and Mn transition elements," Materials Engieneering, vol. 137, pp. 821-824, 2003.

[7] G. Biroli, G. Caglioti, L. Martini, and G. Riontino, "Precipitation kinetics of AA4032 and AA6082: a comparison based on DSC and TEM," Scripta Materialia, vol. 39, no. 2, pp. 197-203, 1998.

[8] G. Mrówka-Nowotnik, "Influence of chemical composition variation and heat treatment on microstructure and mechanical properties of 6xxx alloys," Archives of Materials Science and Engineering, vol. 46, no. 2, pp. 98-107, 2010.

[9] W. F. Miao and D. E. Laughlin, "Precipitation hardening in aluminum alloy 6022," Scripta Materialia, vol. 40, no. 7, pp. 873-878, 1999.

[10] A. K. Gupta, D. J. Lloyd, and S. A. Court, "Precipitation hardening in Al-Mg-Si alloys with and without excess Si," 
Materials Science and Engineering A, vol. 316, no. 1-2, pp. 1117, 2001.

[11] S. Zajac, B. Bengtsson, and C. Jönsson, "Influence of cooling after homogenisation and reheating to extrusion on extrudability and final properties of AA 6063 and AA6082 alloys," Materials Science Forum, vol. 396-402, no. 1, pp. 399-404, 2002.

[12] R. A. Siddiqui, H. A. Abdullah, and K. R. Al-Belushi, "Influence of aging parameters on the mechanical properties of 6063 aluminium alloy," Journal of Materials Processing Technology, vol. 102, no. 1, pp. 234-240, 2000.

[13] S. O. Adeosun, S. A. Balogun, O. I. Sekunowo, and M. A. Usman, "Effects of Heat Treatment on Strength and Ductility of Rolled and Forged Aluminum 6063 Alloy," Journal of Minerals \& Materials Characterization \& Engineering, vol. 9, no. 8, pp. 763-773, 2010.

[14] W. Khraisat and W. Abu Jadayil, "Strengthening aluminum scrap by alloying with iron," Jordan Journal of Mechanical and Industrial Engineering, vol. 4, no. 3, pp. 372-3377, 2010.

[15] D. G. Morris and S. Gunther, "The influence of order on the recovery and recrystallization of a $\mathrm{Fe}_{3} \mathrm{Al}$ alloy," Intermetallics, vol. 3, no. 6, pp. 483-491, 1995.

[16] T. T. Sasaki, T. Ohkubo, and K. Hono, "Microstructure and mechanical properties of bulk nanocrystalline Al-Fe alloy processed by mechanical alloying and spark plasma sintering," Acta Materialia, vol. 57, no. 12, pp. 3529-3538, 2009.

[17] A. Singh, Studies on aluminum-iron ore in-situ particulate composite [M.S. thesis], Department of Metallurgical \& Materials Engineering, National Institute of Technology Rourkela, 2010.

[18] A. Darvishi, A. Maleki, M. M. Atabaki, and M. Zargami, "The mutual effect of iron and manganese on microstructure and mechanical properties of aluminium-silicon alloy," MJoM, vol. 16, no. 1, pp. 11-24, 2010.

[19] M. Kouzeli and A. Mortensen, "Size dependent strengthening in particle reinforced aluminium," Acta Materialia, vol. 50, no. 1, pp. 39-51, 2002.

[20] J. Shih-Chang and C. Sinn-Wen, "The solidification characteristics of 6061 and a356 aluminum alloys and their ceramic particle-reinforced composites," Acta Materialia, vol. 45, no. 12, pp. 4887-4899, 1997.

[21] V. S. Aigbodion and S. B. Hassan, "Effects of silicon carbide reinforcement on microstructure and properties of cast $\mathrm{Al}$ $\mathrm{Si}-\mathrm{Fe} / \mathrm{SiC}$ particulate composites," Materials Science and Engineering A, vol. 447, no. 1-2, pp. 355-360, 2007.

[22] R. A. Karnesky, L. Meng, and D. C. Dunand, "Strengthening mechanisms in aluminum containing coherent $\mathrm{Al}_{3} \mathrm{Sc}$ precipitates and incoherent $\mathrm{Al}_{2} \mathrm{O}_{3}$ dispersoids," Acta Materialia, vol. 55, no. 4, pp. 1299-1308, 2007.

[23] G. Sha, K. O’Reilly, B. Cantor, J. Worth, and R. Hamerton, "Growth related metastable phase selection in a $6 \mathrm{xxx}$ series wrought $\mathrm{Al}$ alloy," Materials Science and Engineering A, vol. 304-306, no. 1-2, pp. 612-616, 2001.

[24] M. Warmuzek, G. Mrówka, and J. Sieniawski, "Influence of the heat treatment on the precipitation of the intermetallic phases in commercial AlMn1FeSi alloy," Journal of Materials Processing Technology, vol. 157-158, pp. 624-632, 2004.

[25] H. Sasaki, N. Kobayashi, K. Kita, J. Nagahora, and A. Inoue, "Nanocrystalline structure and mechanical properties of vapor quenched $\mathrm{Al}-\mathrm{Zr}$-Fe alloy sheets prepared by electronbeam deposition," Materials Transactions, vol. 44, no. 10, pp. 1948-1954, 2003.
[26] S. Zajac, B. Hutchinson, A. Johanson, L. O. Gullman, and R. Lagneborg, "Microstructure control and extrudability of Al-Mg-Si alloys, microalloyed with manganese," Journal De Physique, vol. 3, pp. 251-254, 1993. 

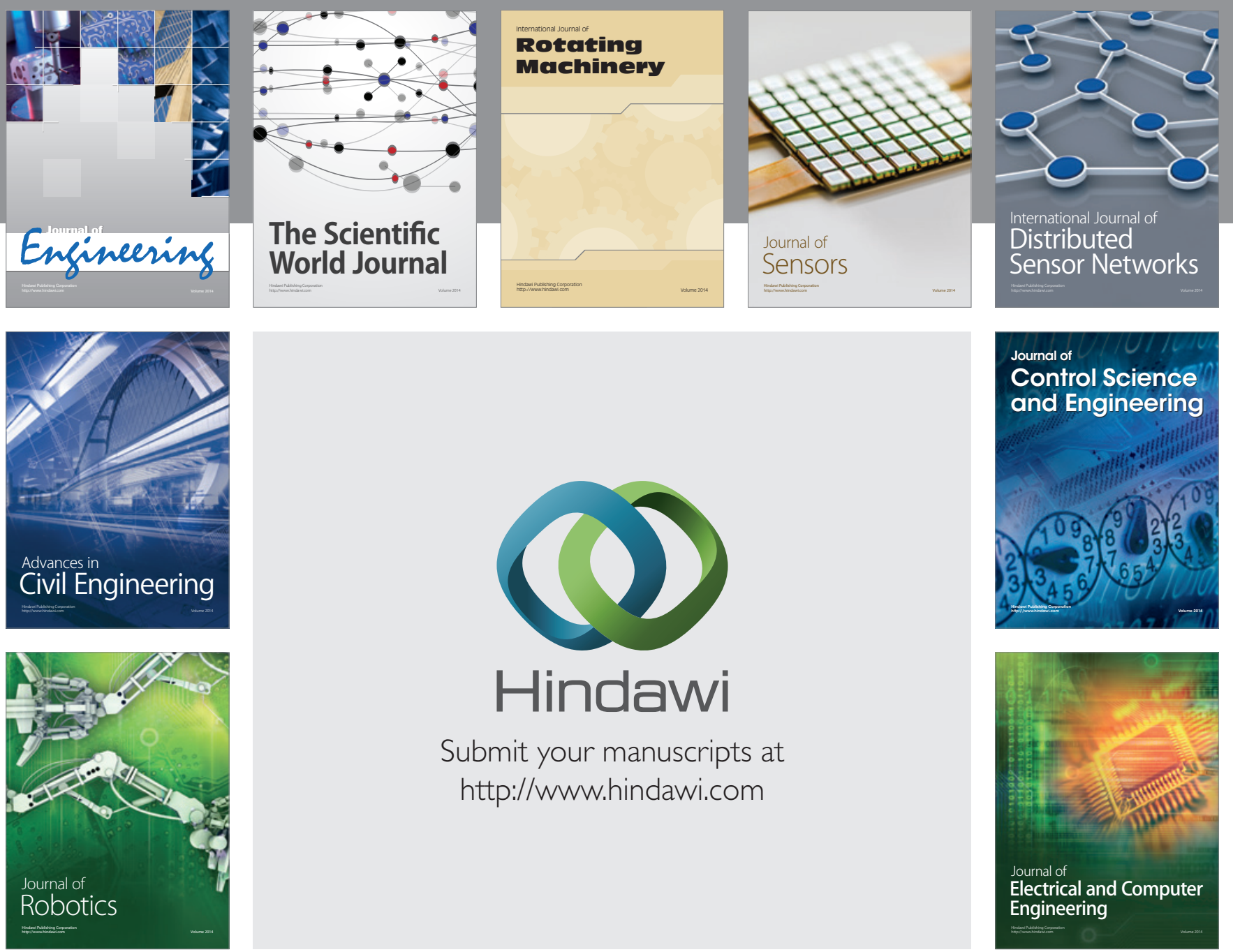

Submit your manuscripts at

http://www.hindawi.com
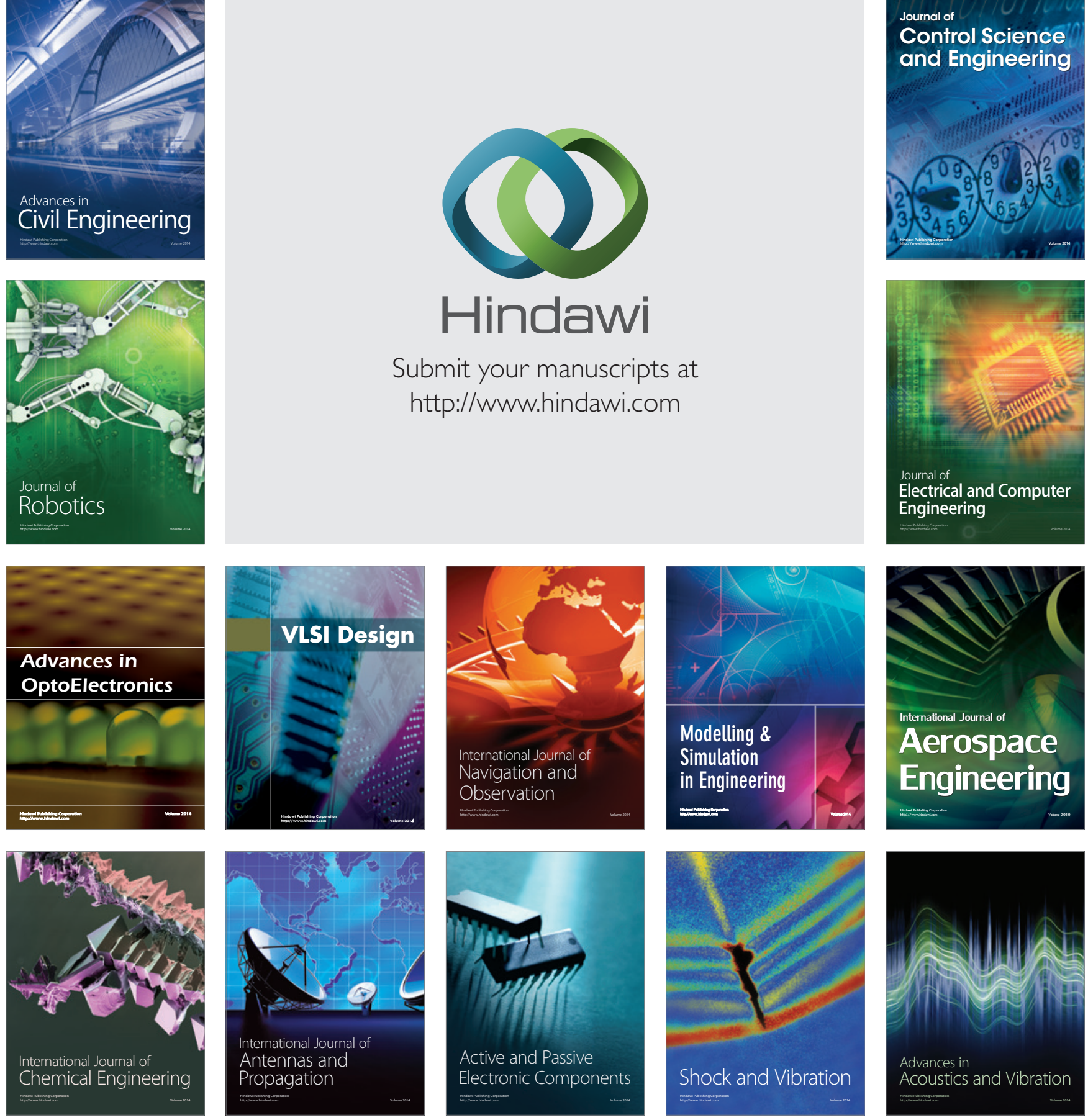